\title{
Nicanor Plaza y Francisco Gazitúa: diálogo en torno a El Caupolicán ${ }^{*}$
}

\section{Nicanor Plaza and Francisco Gazitúa: dialogue about El Caupolicán}

\author{
Pedro Emilio Zamorano Pérez \\ Universidad de Talca \\ pzamoper@utalca.cl
}

Resumen • El presente trabajo construye un diálogo entre dos escultores separados por algunas generaciones, pero unidos por un espacio de formación artística y una tradición común: la Escuela de Bellas Artes de Chile. Esta conversación informa acerca de la vida y la obra de Nicanor Plaza, considerado como uno de los principales maestros de la escultura chilena, de las tradiciones pedagógicas de la escuela y de la obra El Caupolicán, una de sus realizaciones más importantes.

Palabras clave: escultura chilena, Nicanor Plaza, Francisco Gazitúa, El Caupolicán, docencia artística.

Abstract - The following paper creates a dialogue between two sculptors that are separated by a few generations, but that are joined by their artistic formation and a common tradition: the Bellas Artes de Chile School. This dialogue provides information about the life and work of Nicanor Plaza, who is considered to be one of the greatest Chilean artists in Sculpting, and the pedagogic tradition of his art school, as well as information about the work El Caupolicán, one of his most important pieces of art.

Keywords: Chilean Sculpture, Nicanor Plaza, Francisco Gazitúa, El Caupolicán, Art Teaching.

\section{ANTECEDENTES}

Las reflexiones que hace el escultor e investigador chileno Francisco Gazitúa ${ }^{1}$ sobre Nicanor Plaza y su obra El Caupolicán refieren un espacio y una experiencia, salvada la distancia temporal, común: la Facultad de Bellas Artes de la Universidad de Chile, en

\footnotetext{
* Este artículo corresponde al Proyecto Fondecyt No 1085295, «Escultura chilena 1854-1960: el trasluz de su identidad», cuyo investigador responsable es Pedro Emilio Zamorano y sus coinvestigadores Claudio Cortés y Francisco Gazitúa.

1 El presente artículo tiene como base una entrevista al escultor chileno Francisco Gazitúa, quien es coinvestigador del proyecto Fondecyt que origina esta publicación.
} 
donde ambos se formaron y desarrollaron. Nicanor Plaza, además de haber contribuido a la fundación de esa entidad, fue formador de escultores por varias generaciones; Gazitúa, que fue profesor en la misma institución casi cien años después, entre 1966 y 1973, se entronca con la vieja escuela que fundara Plaza, a través de sus maestros Julio Antonio Vázquez, Marta Colvin, Samuel Román y Lily Garafulic. Es que la formación de escultores en la Facultad, a pesar de todos los cambios que hubo en el plantel, mantuvo casi sin alteraciones sustanciales sus tradiciones artísticas y pedagógicas, tanto así que los programas de estudio no sufrieron modificaciones muy profundas. Situación diferente vivió la pintura, que se vio enfrentada de manera más profunda a los debates estéticos y confrontaciones de su época.

En este diálogo, Gazitúa establece una interacción con Plaza siguiendo su huella biográfica, a la vez que analizando una de las obras paradigmáticas del maestro: El Caupolicán. Las preguntas que se hacen a la estatua irán develando cómo se formó el escultor decimonónico, las etapas por las que pasó, los conceptos artísticos que profesaba, su vida y su experiencia de estudio, primero en Chile y luego en Francia. También intentan dar cuenta de las visiones estéticas que tenía Plaza cuando en plena juventud, entre los 22 y los 26 años, realizara El Caupolicán. Con tal propósito se revisarán sus años iniciales en París, los maestros y programas de estudio que tuvo en la École Nationale des Beaux Arts y los conceptos y categorías que allí se profesaban. Al respecto debemos recordar que una cosa son los programas y otra los criterios, tradiciones y culturas no explicitados que subyacen en esos documentos y que forman parte de una tradición oral y de transmisión de un sistema educativo ${ }^{2}$. En ese sentido, la relación maestro-discípulo ha sido la clave en la formación artística en todos los tiempos, y lo fue para él tanto en la Facultad de Bellas Artes, en Chile, como en la École Nationale des Beaux Arts de París.

Hemos querido establecer un diálogo entre estos dos escultores chilenos de distintas épocas a partir de un recorrido biográfico por la vida del maestro decimonónico, que examina una tradición docente y que detiene la mirada en una de sus obras emblemáticas, El Caupolicán ${ }^{3}$. Dicha escultura encierra muchas claves, respecto de las cuales Gazitúa elucida contenidos y tradiciones interesantes de conocer. Las reflexiones que hace sobre Plaza y la referida obra se sintetizan desde distintos puntos de vista, que hemos denominado lecciones.

«Los que hemos sido educadores en artes visuales sabemos que en nuestro campo, poco importan los programas de estudio, ellos proveen de un marco exterior. Lo fundamental no está escrito y jamás podrá estarlo porque el que forma, el maestro que en una primera etapa entrega conocimientos, pero el gran trabajo en el largo plazo consiste en desarrollar la vocación del aprendiz, iniciarlo en un camino que durará toda su vida, que lo llevará al fin a recibir y desarrollar el campo como algo propio a la muerte de su maestro, ese es el fin único de la educación en el arte: es pacto maestro alumno». Entrevista a Francisco Gazitúa.

3 El nombre original de la escultura fue The last of mohicans y fue fundida en bronce. Sus medidas son 2,30 metros y 1 por 1 metro en la base (de 25 centímetros de alto). La obra que sostiene, además, un garrote y un hato de flechas, se encuentra en el cerro Santa Lucía de Santiago. 


\section{PRIMERA LECCIÓN: LOS INICIOS}

Nicanor Plaza, el más inspirado de los artistas chilenos (Yáñez Silva), nació en la localidad rural de Renca, Chile — cinturón chacarero de Santiago- en $1841^{4}$. De su origen humilde y campesino hay pocos antecedentes, aun cuando se sabe que desde pequeño estuvo incorporado a faenas agrícolas.

El señor Plaza, nacido en los alrededores de Santiago, en el lugar de las buenas frutillas [Renca], e hijo de padres pobres pero honrados, hizo sus primeros estudios artísticos en nuestra escuela de escultura, bajo la dirección de su actual director don Ernesto [sic] François, en cuyo establecimiento obtuvo algunos premios que le hicieron acreedor a ser nombrado por el gobierno de Chile pensionado en París (Suárez, 418).

Los inicios de Plaza fueron difíciles, al igual que los de otros escultores nacionales de su tiempo, como José Miguel Blanco (1830-1897) y Virginio Arias (1855-1941); una especie de escuela de la vida a la que Gabriela Mistral, también de raigambre campesina, llamara surco sin fin, como una forma de significar una formación vinculada al rigor y a la naturaleza ${ }^{5}$.

Siendo todavía niño trabajó en la sombrerería de un ciudadano francés, Monsieur Bayle, quien estaba vinculado con el fundador de la enseñanza de la escultura en Chile, el maestro Augusto François (1800-1876) ${ }^{6}$. Benjamín Vicuña Mackenna refiere la siguiente información:

veíase sobre una delgada tablita de alerce una guirnalda de flores copiada del natural por un niño de Renca, que el escultor François, profesor de la Universidad, había sacado de la sombrerería de Bayle, donde era aprendiz, a fin de enseñarle el arte divino de Fidias y Bounarotti. Ese principiante infantil, que comenzó el estudio de la grandiosa cabeza desnuda de Caupolicán y la gentil del Jugador de Chueca, en la copa de felpa de los sombreros del vulgo, llamábase Nicanor Plaza y era a la sazón un travieso muchacho de diez años (125).

A través de ese contacto con François, Plaza ingresó a los 14 años a la clase que dirigía el artista francés, a estudiar escultura ornamental y talla en madera. En esa primera etapa, las condiciones para impartir la docencia eran dificultosas, tanto en lo material como en los aspectos institucionales. De hecho, la enseñanza de la pintura y la escultura no tenían un tronco pedagógico común. Dicha situación fue modificada el año 1858 a través de un decreto del 3 de agosto, firmado por el presidente Manuel Montt y por el ministro Rafael Sotomayor, en que se reformaba la Academia de Pintura y se le confería

$4 \quad$ Nicanor Plaza nació, según consta en registro parroquial de Renca, el 21 de febrero de 1841. Falleció en Florencia, Italia, el 7 de diciembre de 1918. Hay antecedentes de que sus años postreros fueron difíciles. En 1900 se le habían amputado algunos dedos de su mano izquierda y después pierde un brazo. Sin embargo, siguió trabajando. Las obras Prólogo y Epílogo, ubicadas en el Teatro Municipal de Santiago, corresponden a sus últimas creaciones hechas en Italia.

5 A diferencia de muchos pintores chilenos de la segunda mitad del siglo XIX, vinculados mayoritariamente a la oligarquía local, los escultores proceden de sectores sociales medios, e incluso bajos, y de sectores campesinos. La escultura chilena de esa época pareciera ser una profesión para pobres, excluida de ello por cierto Rebeca Matte.

6 Augusto François llega a Chile en 1850 contratado por la Orden de los Franciscanos para sostener un taller de imágenes sacras. En 1854 asume la dirección de la Escuela de Escultura Ornamental y Dibujo de Relieves para artesanos. 
a esos estudios un rango universitario 7 . La medida, aparte de uniformar la enseñanza de dichas materias, proveía de una estructura académica a esos estudios y establecía dos concursos anuales, además de premios y pensiones en el extranjero para los alumnos más meritorios $^{8}$.

\section{SEGUNDA LECCIÓN: EL VIAJE}

El becar a los artistas más destacados para que fueran a formarse a Europa fue parte en Chile de una política de Estado. El destino de la mayoría de los pintores y escultores fueron las academias tradicionales de arte, como la École Nationale des Beaux Arts de París. En 1863, Plaza fue pensionado por el gobierno chileno para seguir sus estudios en la capital francesa, contando además con una ayuda económica de Matías Cousiño. Ahí tuvo estrechos vínculos de amistad con dos artistas chilenos: el escultor José Miguel Blanco y el pintor Miguel Campos. En ese momento tenía su taller en Rue Humbolt, 25.

En carta enviada desde París a su padre el 30 de junio de 1867, José Miguel Blanco señala: «Yo estoy viviendo con Nicanor, cuando me escriban mándenme las cartas con esta dirección «Monsieur N. Plaza`, para entregar a Blanco» (Blanco, 6). En París, Plaza se incorporó al taller de François Jouffroy $(1806-1882)^{9}$, con quien estudió por tres años, y en 1866 abrió en la misma ciudad un taller propio, donde realizó un importante número de obras. De esa época son El Caupolicán, El jugador de chueca, Magdalena y Amor cautivo, entre otras, obras que, según Vicente Grez, dieron al escultor fama honorable en Francia y popularizaron su nombre en Chile.

Este viaje fue quizá el más importante estímulo en su formación y marcó de alguna forma el resto de su vida. El hecho de estudiar en Europa para un joven artista chileno implicaba, por una parte, la ansiedad positiva, el viaje, conocer contextos culturales distintos, otros espacios artísticos considerados como más desarrollados, pero por otra parte estaba el lado más traumático, las vivencias perturbadoras, las incertidumbres y el desarraigo. Una experiencia de dulce y agraz que también tuvo el escultor José Miguel Blanco, quien había viajado a la capital francesa en mayo de $1867^{10}$. El autor del Padre Bartolomé de Las Casas amamantado por una india (Museo O’Higginiano de Talca) recuerda en su epistolario su relación con Plaza:

$7 \quad$ El artículo $1^{\circ}$ del referido documento establecía una sección de Bellas Artes en el Departamento Universitario del Instituto Nacional e integraba las especialidades de Pintura y Dibujo Natural, Arquitectura y Escultura.

$8 \quad$ El 7 de enero de 1859, un nuevo Decreto Supremo reorganizaba en forma más completa la cátedra de Escultura, intentando establecer una mejor armonía entre los aspectos prácticos y teóricos de la disciplina. Así, se dividen las actividades en dos secciones: estatuaria y ornamental. Bajo este contexto se otorga la oportunidad de impartir la enseñanza de la disciplina en el país bajo una estructura metodológica, con programas de estudio y con el reconocimiento y apoyo del Estado. Saludable fue también la política de enviar a los egresados más meritorios a continuar su formación en el Viejo Continente.

9 Jouffroy se formó en la École des Beaux-Arts. Obtuvo el Premio Roma, vinculándose ideológicamente a la tradición neoclásica francesa.

10 Decreto $\mathrm{N}^{\circ}$ 1.218, del 7 de mayo de 1867. El escultor fue becado para viajar a Europa con el objetivo de estudiar grabado, aplicado al trabajo de monedas en París. 
Todos los hombres son buenos, a mi parecer, pero cuando se trata con ellos del pie que cojean. Así padre, Mr. François es un buen hombre, muy bien lo conozco, pero si yo tuviera que tratar con él sobre algún negocio de dinero, estoy seguro de lo que resultaría, porque su defecto es la avaricia. Nicanor [Plaza] es un buen joven, tiene muy buenas cualidades, pero es orgulloso como él solo. Yo no me conozco la maña o el defecto que tengo, pero Nicanor me dice que soy orgulloso, y Mr. François que soy taimado y muy «cabezudo». No sé cuál de los dos tendrá razón (Blanco, 20).

No todo fue positivo para los artistas nacionales en París. Tenían que adaptarse a un mundo distinto, con profesores, conceptos y aprendizajes ajenos a su cultura y formas de vida. La École estaba hecha para franceses; en los concursos más importantes, como el Premio Roma, no se admitían extranjeros.

El escultor conoció bien esos problemas y privaciones, especialmente cuando la ciudad estuvo expuesta a los peligros de la guerra. Según Benjamín Vicuña Subercaseaux, Plaza «habría comido ratones durante el sitio de 1870 y enterrado sus obras en un sótano para defenderlas de las balas prusianas» (200).

\section{TERCERA LECCIÓN: LA ÉCOLE NATIONALE DES BEAUX ARTS}

La entidad había sido fundada en 1648 por el cardenal Mazarino, bajo el reinado de Luis XIV, sobre la tradición de la Academia de Vasari en Florencia. Los parámetros estéticos de la École se vinculaban con conceptos clasicistas de raigambre grecorromana. De hecho, el máximo reconocimiento que entregaba la entidad era el Premio Roma, que otorgaba a los artistas una estadía de cuatro años en la Academia de Francia de esa ciudad $^{11}$. La institución tenía ya más de 200 años cuando ingresa el artista chileno, quien es admitido en la Gran École - École des Beaux Arts de París, privilegio que equivalía a contarse entre los mejores escultores jóvenes del mundo. El escultor nacional entró a una especie de lugar sagrado, lleno de tradiciones y obras, que encerraba en sus muros una historia entroncada con los artistas griegos y romanos. La magia de esos espacios de formación es comentada por la escultora Lily Garafulic, cuando se refiere a la Facultad de Bellas Artes de Chile: «La Facultad sigue hacia el futuro, pero debe siempre volver donde están sus muertos, debe volver a conversar con los espíritus. Ahí está todo, en las paredes y el piso. Ahí está la tradición, ahí está todo, escondida entre los ladrillos. Todavía está escondida» (cit. en Gazitúa, 52).

A este respecto Gazitúa agrega lo siguiente:

La esencia de la enseñanza es entonces la escuela misma: su transcurrir en el tiempo, las historias de los profesores y alumnos, la manera como entra la luz a los talleres, el olor de los talleres, las esculturas griegas y sus copias, la biblioteca, la arcilla en los depósitos, amasada por generaciones de alumnos durante 200 años. Los detractores, defensores y enemigos de la escuela, los escultores, maestros muertos y los que heredaron el lugar, todo eso, lo que está escondido entre los ladrillos del edificio ${ }^{12}$.

11 En 1663 y bajo el reinado de Luis XIV se creó este premio anual, que concedía a los jóvenes pintores, escultores y arquitectos una estancia de cuatro años, con cargo al rey, en la Academia de Francia en Roma.

12 Entrevista a Francisco Gazitúa. 
Plaza se empapa de ese ambiente, de esa pedagogía invisible, de esa tradición escultórica encerrada entre los muros del establecimiento. En ese contexto y en plena juventud realiza El Caupolicán ${ }^{13}$, obra que corresponde a un trabajo del programa académico que se exigía a los alumnos avanzados: una figura de pie a tamaño natural ${ }^{14}$. Una escultura de similares características a El roto chileno, que su discípulo Virginio Arias produjera una década después, cumpliendo el mismo programa.

El tema de la figura de pie a tamaño natural se instituye también en la Escuela de Bellas Artes de Chile, como paso obligatorio en el programa de segundo año para los alumnos de escultura, ello hasta la propia generación de Gazitúa.

\section{CUARTA LECCIÓN: BÚSQUEDA DEL TEMA O CONTENIDO LITERARIO DE LA ESCULTURA}

El arte de la escultura equilibra, en tanto experiencia formativa, habilidades, conocimientos técnicos, creatividad y dones poéticos. Además de ello, es necesario poseer una cultura cimentada en la historia, la estética y la literatura. El oficio práctico lleva al escultor a combinar la manualidad artesana con un legado de cultura y sensibilidad.

En la escultura del siglo XIX y comienzos del XX había una preponderancia del contenido (tema) por sobre las argumentaciones propiamente estéticas. Según Gutiérrez Viñuales las esculturas eran hechas, sobre todo en la América decimonónica, para glorificar o conmemorar un hecho o personaje relevante (327). En las estatuas supraindividuales, concepto acuñado por Voionmaa Tanner (76), que tenían la primacía en Chile en los años iniciales de la República, o en los retratos, más abundantes durante la segunda mitad del siglo XIX, había una supeditación de la obra a un contenido histórico, alegórico o literario. El escultor, que actuaba como ilustrador e intérprete de estos temas ${ }^{15}$, conciliaba su trabajo creativo con la necesidad de vehicular conceptos de solemnidad y veracidad que exigía la obra. Antes de poner la arcilla en el caballete era menester adecuar la narrativa literaria con la propuesta estética. Cobraba aquí importancia el conocimiento ilustrado del artista, el que era provisto por las propias instancias académicas, que contaban con cátedras de literatura y cultura general. En el caso de la École Nationale des Beaux Arts, los catedráticos de dichas materias fueron León Heu-

13 Según información aportada por Enrique Melcherts, Plaza ejecutó en 1863, en yeso, su Caupolicán. Al año siguiente realizó copias en bronce y trajo una de ellas a la Exposición Nacional de Artes e Industrias de 1872. La obra figura en el catálogo de la muestra con el número 239, como de propiedad de don Luis Cousiño. Meltcherts agrega que un amigo norteamericano del escultor compró en París una copia de la obra y la exhibió en la Exposición Internacional de Filadelfia de 1876, ganando allí una Primera Medalla (48).

Víctor Carvacho, por su parte, señala que mientras Plaza estudiaba con Jouffroy, el gobierno de Estados Unidos convocó a un concurso internacional para perpetuar la memoria del «último de los mohicanos». En el certamen participó Plaza con un proyecto que tituló The last of the Mohicans, que no recibió distinción (191).

14 El boceto de esta escultura, en poder del Instituto Cultural de Providencia, tiene su origen probablemente en el concurso Prix Lamaire, que exigía uno de 35 centímetros de altura. El agrandamiento a tamaño natural calza en el esquema de ese certamen, donde los alumnos podían trabajar fuera de la escuela.

15 Esta imposición temática, además de la correspondiente sujeción a los preceptos neoclásicos, conoce algunos niveles de libertad en la obra de algunos artistas de fines de siglo, entre ellos Augusto Rodin. El verdadero proceso de liberación se inicia durante el siglo XX, con la generación de Brancusi. 
zey (1831-1922) y Eugène Viollet le-Duc (1814-1879) ${ }^{16}$, en tanto que en su congénere nacional actuaba como profesor en estudios teóricos Enrique Nercaseau y Morán (18541925). Junto al apogeo histórico y literario, y por influjo del romanticismo, comienzan durante la segunda mitad del siglo XIX a surgir temas vinculados a héroes exóticos de culturas de ultramar. En ese sentido, El Caupolicán o Tamenund calzan perfecto con el esquema vinculado al indio ${ }^{17}$.

\section{QUINTA LECCIÓN: DIEZ PASOS ESCULTÓRICOS PARA LLEGAR AL MONUMENTO}

Resuelta la argumentación literaria comenzaban las etapas propiamente escultóricas. Al respecto Gazitúa señala trece pasos:

1. Búsqueda de un modelo

2. Búsqueda de una pose

3. Encuentro del esquema de volúmenes siguiendo alguno de los modelos clásicos

4. Adecuación de la forma a los preceptos estilísticos

5. Vestuario y ambientación histórica

6. Boceto en arcilla de 35 centímetros

7. Herramientas

8. Arcilla

16 Los ramos teóricos eran Historia y arqueología, Historia del arte y estética, Historia general y Literatura, asignaturas que tenían una duración de 3 años (Reglément, 10).

17 El tema del «indio» en la literatura, y por consecuencia en la estatuaria americana, constituye quizás una de las paradojas más interesantes de la época. A modo de ejemplo, en la Plaza de Armas de Santiago está el Monumento a la libertad de América, de Francesco Orsolino. El motivo central está constituido por una india, bajo los códigos formales de la academia, quien recibe el testimonio de la libertad de parte de una diosa helena, probablemente Atenea. Prácticamente todos los discípulos chilenos del escultor Nicanor Plaza tocan también el tema indígena: Virginio Arias realiza la obra Madre Araucana y José Miguel Blanco El Padre las Casas amamantado por una india y Galvarino. La obra de Nicanor Plaza El Caupolicán (de la voz mapudungún 〈Kallfu-likan`, pedernal azul) también vive su tragedia y muerte al comienzo de la guerra de Arauco, que duraría 400 años, hasta los inicios del siglo XX, fecha de la instalación de la escultura en su roca en el cerro Huelén.

Rubén Darío, en su poema "Caupolicán», recuerda también al personaje y la obra de Plaza.

"Es algo formidable que vio la vieja raza:

robusto tronco de árbol al hombro de un

campeón salvaje y aguerrido, cuya fornida maza

blandiera el brazo de Hércules, o el brazo de

Sansón.

Por casco sus cabellos, su pecho por coraza, pudiera tal guerrero, de Arauco en la región, lancero de los bosques, Nemrod que todo caza, desjarretar un toro, o estrangular un león.

Anduvo, anduvo, anduvo. Le vio la luz del día, le vio la tarde pálida, le vio la noche fría, y siempre el tronco de árbol a cuestas del titán. ¿El Toqui, el Toqui! clama la conmovida casta. Anduvo, anduvo, anduvo. La aurora dijo:

〈Basta`, e irguiose la alta frente del gran Caupolicán». 
9. Anatomía

10. Agrandamiento del boceto a tamaño estatuario

11. Copia en yeso

12. Fundición o tallado en mármol

13. Emplazamiento

\section{SEXTA LECCIÓN: BÚSQUEDA DE MODELO}

El primer paso en la enseñanza consistía en seleccionar los modelos adecuados a la historia que narraba la obra. El escogido para El Caupolicán es sin duda del tipo racial que llamamos hoy caucásico, con proporciones anatómicas sujetas al canon clásico. En esa época se buscaba bailarines, actores o atletas, que oficiaban como modelos ${ }^{18}$.

Un tema crucial en la educación de Plaza fue aprender a hacer posar a su modelo, ya que la escultura de la época dependía absolutamente de éste. Se podría afirmar — siguiendo a Gazitúa- que el escultor actuaba como intérprete de una partitura escrita en el cuerpo humano, que se va escaneando momento a momento y desde todos los puntos de vista. El modelo tiene que mantener la pose durante horas y días, mientras la información va siendo fijada en el boceto.

\section{SÉPTIMA LECCIÓN: ESQUEMA VOLUMÉTRICO DEL MONUMENTO EN RELACIÓN A LOS MODELOS CLÁSICOS}

El modelo clásico imponía sus contenidos temáticos a la vez que sus preceptos formales. El canon, en tanto conjunto de reglas y proporciones ideales asociadas a la figura humana, fue un requisito importante en la formación de escultores durante el siglo XIX ${ }^{19}$. Esta regla de oro establecía una medida fundamental, tomada del hombre bien constituido, cuyo elemento central era la cabeza. A partir de ello se derivaban distintas relaciones de tamaño, que se aplicaban al resto de la anatomía. Esos conceptos, que fueron centrales en la pedagogía de la École, llegan a Chile con la creación de la Academia de Pintura en 1849. Su primer director, el italiano Alejandro Cicarelli, en el discurso de fundación de la entidad comentaba lo siguiente:

A fin de que los niños dibujasen bien la figura del cuerpo humano, los griegos le hacían aprender la anatomía, i la denominación de las partes del cuerpo entero, con las proporciones que existían entre ellas. Se daba a un alumno el solo dato de un dedo, o de un ojo de un tamaño señalado, i él sabía en virtud de estas reglas determinar el resto del brazo i la cabeza.

18 Este punto es polémico, pues parte de la revolución anti académica de su contemporáneo Rodin fue despedir a los actores y trabajar con gente de la calle.

19 Los cánones usados con mayor frecuencia fueron el de Policleto (siglo V a. C.), que establecía una altura del cuerpo de siete cabezas, y el de Lisipo de Sicione (siglo IV a. C.), que determinaba una altura del cuerpo de ocho cabezas. 
El canon asociaba consideraciones estéticas, vinculadas con la belleza y la armonía, con correspondencias y simbolismos y criterios de valor. En el mundo antiguo este arquetipo estaba reservado para dioses y atletas, en tanto que durante el siglo XIX lo estuvo para los personajes principales del mundo político y de la élite social. Es decir, la perfección formal - lo estético- era asociada a los valores éticos, de tal manera que lo hermoso y lo bueno se fundían en un solo concepto. Estos arquetipos van generando modelos que se validan y transmiten desde el espacio académico.

La reedición iconográfica clasicista que se produce en Europa hacia fines del siglo XVIII no está referida exclusivamente al idealismo del siglo de Pericles. El s. IV a.C. y sobre todo las escuelas helenísticas de Atenas y Rodas son vistas con especial atención por los escultores decimonónicos. Por ejemplo, el esquema de piernas separadas que posee El Caupolicán tiene su origen en la escultura helenística El gladiador Borghese, de Agasio de Éfeso, datada en el siglo I a.C. y que se encuentra en el Louvre. La posición de las piernas y el eje de los hombros define para esta obra una posición conocida como contraposto, término italiano usado para señalar la oposición armónica de las distintas partes del cuerpo que, junto con romper la ley de la frontalidad (por un quiebre de los «ejes» en forma de espiral), proporciona una sensación de movimiento a la figura humana $^{20}$. También se hace más dramático el claroscuro de la escultura, abandonando los grises (pasajes) y comenzando a trabajar con sombras profundas (pantallas). La obra de Plaza sigue el esquema del Capanee (1832), piernas separadas y ejes en espiral, Grand Prix de Rome Sculpture, de su maestro Jouffroy (Colección École Nationale des Beaux Arts de París). Este esquema escultórico corresponde también al David y al Neptuno y Tritón (1620), realizadas por Bernini.

\section{OCTAVA LECCIÓN: COMPOSICIÓN, EJES Y PUNTOS MÁXIMOS}

Un buen método para entender las proporciones en una escultura era a través del empleo de ejes compositivos, que se marcaban en el boceto de arcilla. Ese sistema de líneas (ejes), que unía las articulaciones más importantes, sus puntos máximos, era usado en escultura para medir de lejos el modelo, con certeza milimétrica, sin emplear para ello un metro. Según Gazitúa, el ojo adiestrado del escultor académico tiene que ser capaz de medir en forma exacta el modelo, a distancia máxima de un metro.

Los ejes de El Caupolicán forman un espiral que se tuerce de izquierda a derecha, de tal modo que el de los pies cobra una posición perpendicular al de los hombros. La visión frontal muestra los ejes quebrados, lo que contribuye al dinamismo de la figura.

20 El contraposto se usa en la escultura para dar sensación de movimiento. Una de las piernas está fija en el suelo, como si fuera una columna, y la otra se adelanta, los brazos hacen lo propio, mientras la cabeza mira hacia un lado simulando un paso. 


\section{NOVENA LECCIÓN: BOCETO- MODELADO}

Uno de los pasos más importantes en la realización de una escultura académica consistía en la confección de un boceto de arcilla, de 35 centímetros de altura, sobre una estructura de alambre. Dicha estructura es el equivalente al esqueleto alrededor del cual se disponen los músculos. En palabras de Sargeant Jagger, en ella deberán estar todas las proporciones de la figura (74). La estructura se encuentra fijada a un tablero giratorio de madera, sostenido sobre un trípode de 1,30 metros. La medida de 35 centímetros de altura del boceto era útil, ya que multiplicada por cinco daba el tamaño natural y por siete el tamaño estatuario ${ }^{21}$.

El modelo desnudo de El Caupolicán y el pequeño boceto en arcilla se situaban frente a frente, durante semanas, sobre caballetes giratorios, en un ritual en que el escultor los hacía girar cada cinco minutos para verlos mejor. Girando ambas plataformas constantemente, el boceto iba creciendo paulatinamente sin estancarse en un solo punto de vista. Esta carencia de punto fijo en el proceso creativo abre el primer camino al movimiento de la escultura, al tiempo que abre un segundo camino en el futuro, simulando el mismo movimiento en círculos que hará el espectador en el lugar de emplazamiento, frente a la futura estatua.

La contemplación activa de la fascinante relación entre estos tres sujetos en movimiento, el escultor, el boceto de arcilla y el modelo vivo, fue la lección clave para entender la base de todo el lenguaje escultórico: el modelado.

\section{DÉCIMA LECCIÓN: DISTANCIA}

El escultor académico trabajó siempre desde un mínimo de distancia de tres metros del modelo y de 10 centímetros del boceto en arcilla, que jamás tocaba con la mano, pues tenía como intermediario una herramienta que le evitaba el sobajeo de la greda. Según Gazitúa, es necesario observar a un mínimo de un metro el boceto, pues esa mirada desde la distancia produce una imagen con una fuerte línea de contorno, que adelanta la silueta característica que resolverá, en el espacio público, el futuro observador del monumento. El Caupolicán cumple con las dos miradas. Desde lejos la figura se capta claramente por el énfasis de los músculos y el movimiento; de cerca se percibe un exacto modelado.

\section{UNDÉCIMA LECCIÓN: HERRAMIENTAS}

El equipo reglamentario de los escultores de la época era liviano y básico. Consistía en cuatro calibres de medir, de cuatro metros a veinte centímetros cada uno, quince estacas

21 Los ingleses trabajan el boceto a 2 pies (60 centímetros aproximadamente), y para ser trasladado a tamaño heroico lo multiplican por 6 (12 pies o 3,60 metros). 
de madera de limón, un compás de conversión 1:2, un compás de conversión 1:3 y de $1: 6$, doce raspadores y cortadores, una plomada portátil y un trípode de plomada y un metro.

\section{DUODÉCIMA LECCIÓN: ARCILLA}

La arcilla y su manejo es un tema muy relevante para el escultor; más aún para el principiante. Se guardaba en grandes cajones y había que mantenerla con la humedad justa, amasándola para sacar el aire. Mantener la arcilla a punto, según Gazitúa, es algo tan difícil como afinar un violín. Es necesario conseguir una familiaridad total con la greda; evitando que se pegue en la mano, los dedos la tocan sólo para darle la forma aproximada que tendrá en la escultura. Al terminar el trabajo, había que cubrir el boceto con una infinidad de trapos para mantener la greda húmeda, en un ritual de una vez al día en invierno y tres en verano. Cuando la escultura estaba terminada, la arcilla era cubierta por el yeso de los moldes para obtener la figura en positivo. La figura en arcilla perdía su forma y la greda volvía a sus cajones, para ser utilizada nuevamente siguiendo los mismos procedimientos.

La greda que trabajó Nicanor Plaza en la École tenía ya doscientos años de amasado. Así, guardaba en sus moléculas el recuerdo de todos los intentos de miles de alumnos, un constante hacer y deshacer, como los hilos del manto de Penélope.

\section{DECIMOTERCERA LECCIÓN: ANATOMÍA}

El modelado del boceto se ceñía a un estricto análisis anatómico. Tanto así que había un concurso especial en la École, el Prix Hugiuer, que medía el conocimiento de anatomía (Reglèment, 29). Todos los músculos debían estar a la vista (imagen écorché).

En la $10^{\text {a }}$ sección del Proyecto de Plan de Estudios de la Escuela de Bellas Artes de Chile, sometido a consideración del Consejo de Instrucción Pública el 5 de junio de 1905, se consideraba la asignatura de Anatomía de las Formas. Estas materias comprendían la enseñanza descriptiva del sistema óseo y muscular, articulaciones, ejercicios, preparaciones, elementos de fisiología y expresión fisonómica. El profesor de la asignatura fue David Benavente.

\section{DECIMOCUARTA LECCIÓN: CABEZA}

Había dos labores fundamentales para el escultor de la época: el boceto, donde se mostraba en pequeña escala cómo quedaría la obra a tamaño natural, y la cabeza, con la que el escultor mostraba, a escala 1-1, ese detalle de la obra. 
Desde el punto de vista anatómico, la cabeza del modelo de El Caupolicán, a pesar de su nariz aguileña, no coincidía demasiado con el prototipo racial mongoloide de los primeros pobladores de América. Ellos, pieles rojas, mapuches, incas, etc., presentan doble párpado y pómulos salientes. Según consigna el Reglamento de la École, La tête d'expresion era el concurso más importante en la entidad, después del Premio Roma (Reglèment, 28). El alumno debía crear una cabeza escultórica que fuera el resumen de toda su obra.

\section{DECIMOQUINTA LECCIÓN: VESTUARIO Y AMBIENTACIÓN HISTÓRICA}

La escultura, en boceto, se consideraba terminada en su etapa desnuda. Ahí se corregía, se agregaba energía o importancia a las partes. Después de todo ese trabajo se vestía. Nicanor Plaza vistió su estatua de indio norteamericano. En opinión de Gazitúa el taparrabos no molesta, a diferencia de los aros, que eliminaría. El penacho de plumas constituye un muy interesante contrabalance de la cabeza. La vestimenta de la obra ha sido cuestionada con el argumento de que los araucanos nunca usaron plumas en la cabeza y que tampoco el arco y el carcaj fueron parte de su indumentaria habitual.

\section{DECIMOSEXTA LECCIÓN: ESTILO}

Resulta difícil clasificar a El Caupolicán dentro de un estilo definido. La obra fue realizada durante la segunda mitad del siglo XIX, en un momento de eclecticismo en las artes visuales. Aun así, desde el punto de vista del análisis de la forma, la obra expresa una clara tendencia barroca. En este sentido, El Caupolicán sigue el esquema del David de Bernini, el más influyente de los escultores del siglo XVII. Hay en ella un naturalismo robusto, intencionado en la monumentalidad, con un despliegue libre y dinámico de las formas en el espacio. Si se analizan los postulados que Wölfflin elaboró en su obra Principios de la historia del arte (1915), donde extrae varios pares de conceptos, podríamos señalar que El Caupolicán es más profundo que plano, de forma más abierta que cerrada, y que hay en él más multiplicidad que unidad. Es decir, revela en forma más nítida su filiación con la estética que caracterizó a algunas escuelas del Siglo de Oro. A ello debemos sumar la expresión del rostro. El dinamismo que generan los ejes de la cadera y los hombros y su musculatura exuberante resulta distante de la suavidad clásica.

\section{DECIMOSÉPTIMA LECCIÓN: MOVIMIENTO}

Una de las claves del significado escultórico de la obra de Plaza está dada por el movimiento de los volúmenes y por los ejes diagonales que articulan la composición. Hombros, brazos, cadera y piernas dibujan poderosas líneas oblicuas que intencionan, inclu- 
so, un movimiento giratorio de la obra. El Caupolicán recuerda, bajo este punto de vista, al Laocoonte helenístico de la Escuela de Rodas. De hecho, el hombro del sacerdote troyano es muy parecido al del indígena americano.

La pregunta por el movimiento es un tema que obsesionó a los escultores de la época. En el caso de El Caupolicán, tanto en el modelo como en la escultura los huesos y músculos se estructuran formando cadenas de fuerza, desde el suelo de bronce y roca. Los pies son sólidas bases, donde recae finalmente la fuerza de gravedad. Todo el peso del cuerpo, que empuja hacia abajo, devuelve las mismas fuerzas desde abajo hacia arriba a través de las piernas, especialmente la izquierda, que forma una columna con el torso. Los brazos presionan el arco hacia abajo y, a través de él, toda la energía vuelve nuevamente al suelo para subir otra vez, en un movimiento que sólo depende de la mirada del espectador. Ese flujo constante de energías ininterrumpidas es lo que produce aquí el equivalente escultórico del movimiento.

El Caupolicán, además de su lección literaria o histórica, deja una enseñanza de movimiento en una estatua, sobria, sin las contorsiones y adornos excesivos a los que generalmente recurrían los escultores de la época. Hay que considerar también que Nicanor Plaza trabaja aquí un monumento de una sola figura, donde resulta más difícil crear la sensación de acción y movimiento que en los grupos escultóricos, tales como Laocoonte, de Agesandro de Rodas, o Las tres gracias, del neoclásico Antonio Canova.

\section{DECIMOCTAVA LECCIÓN: LUZ}

La obra de Plaza fue hecha para la luz del sol. Desde un principio el escultor sabía que las estatuas desaparecían al ponerse el sol. El Caupolicán nace en París, en un taller donde los alumnos trabajaron con la luz tamizada que entraba por las ventanas que dan al lado norte. En Chile, esa misma luz se obtiene a través de las ventanas orientadas hacia el sur. La luz del norte en el hemisferio sur es el rayo de sol directo sobre la obra, que con su potencia no permite ver los semitonos y con los años deja ciego al escultor.

En la época no había luz artificial. El alumbrado a gas no alcanzaba a iluminar las estatuas en la noche, de manera que las obras cobraban forma cada día. En la madrugada veían pasar las horas cambiando de expresión según el trabajo de la luz en los volúmenes de su rostro y cuerpo. A la puesta de sol y enfocadas desde el lado de la ciudad, las estatuas eran casi doradas, mientras que se volvían negras con las lluvias de invierno y grises con las nieblas de otoño.

\section{DECIMONOVENA LECCIÓN: EMPLAZAMIENTO}

La escultura de esa época no estaba hecha para ser aprehendida a través del tacto. El primero en plantear un tipo de estatua cercana, táctil, fue Rodin veinte años después de la realización de El Caupolicán. Según Robert Descarnes, el escultor francés quiso emplazar Los Burgueses de Calais en el suelo de la plaza, pero no se lo permitieron (106-115). 
El Caupolicán fue hecho, como la mayoría de las estatuas de ese entonces, para ser instalado en un lugar alto, aislado de la gente, en pedestales arquitectónicos de gran tamaño ${ }^{22}$. Esta forma de emplazar la obra fue concebida por el escultor desde la realización de los bocetos.

El Caupolicán, terminado en París en 1886, mantuvo un emplazamiento viajero en sus primeros años. Primero peregrinó a América del Norte, a una exposición concurso con el nombre The last of Mohicans, donde no tuvo éxito; posteriormente, en 1887, la obra es trasladada a Chile, quedando en poder del Museo Nacional de Bellas Artes. En su sesión del 10 de mayo de 1910, el Consejo de Bellas Artes toma el siguiente acuerdo (Acuerdo $\mathrm{N}^{\circ}$ 2)

Contestar a los señores Vicuña, Mac Iver i Ried que el Consejo ve con agrado su iniciativa para hermosear el principal paseo de la capital y que cree que sería preferible colocar en la nueva subida del cerro Santa Lucía, la estatua en bronce del héroe más caracterizado de la raza araucana, de El Caupolicán, para lo cual podría pedir autorización al Gobierno para ceder a la ciudad de Santiago la escultura en bronce de don Nicanor Plaza que hay en el Museo $^{23}$.

Otro acuerdo de la Comisión, tomado en la sesión del 23 de junio de 1910, señala la necesidad de «Impartir las órdenes necesarias para que se entregue a la Municipalidad la estatua El Caupolicán a fin de que se coloque en la nueva subida del cerro por la calle de la Merced $»^{24}$. En la sesión del 13 de agosto de ese año se acordó (Acuerdo $\mathrm{N}^{\circ} 4$ ) «Nombrar a los señores Cousiño, Fabres i Alfonso para que vigilen la colocación de la estatua de El Caupolicán en la nueva subida del cerro Santa Lucía, debiendo comunicarse este acuerdo a la Municipalidad manifestándole que se ha contado con la benevolencia de la Corporación».

De ese modo, la obra fue ubicada en 1910, más de veinte años después de su nacimiento en la École de París, en una terraza a cien metros aproximadamente sobre la ciudad de Santiago, en la mitad del camino hacia la cima del cerro, donde quedó definitivamente emplazada sobre una gran roca de andesita, una variedad de basalto de fracturación pentagónica ${ }^{25}$.

Este plinto de roca sigue la tradición europea del escultor Falconet, quien en 1766 emplazó su Monumento ecuestre a Pedro el Grande, en San Petesburgo, en la cima de una gran roca. Similar es el caso de la escultura de Virginio Arias El roto chileno (1882), ubicada en la Plaza Yungay de Santiago. El pedestal natural de El Caupolicán se relaciona también con las rocas, soporte de las alegorías de los ríos, metáfora de la integración de las esculturas con la naturaleza. Esa imbricación se logra en obras tales como La fontana de los cuatro ríos, de Bernini, en Plaza Navona de Roma.

22 El Caupolicán tiene varias copias en Chile, todas ellas en distintos emplazamientos. Es el caso de las obras existentes en Rengo, el Club Hípico, la Universidad del Bío Bío y la Universidad de Concepción.

23 Acta de la Comisión de Bellas Artes, de 10 de mayo de 1910, documento perteneciente al Centro de Documentación de la Biblioteca del Museo Nacional de Bellas Artes de Chile, página 115.

24 Acta de la Comisión de Bellas Artes, de 23 de junio de 1910, documento perteneciente al Centro de Documentación de la Biblioteca del Museo Nacional de Bellas Artes de Chile, página 127.

25 Las medidas del emplazamiento son 7 × 8 × 10 metros, en su vista principal desde la Plaza. La roca tiene la forma triangular de las bases o pedestales de la época. 


\section{VIGÉSIMA LECCIÓN: ESPACIALIDAD DE LA ESTATUA}

La escultura es un arte que se muestra simultáneamente en tres dimensiones. Por tal razón puede, al mismo tiempo, ser percibida desde todos sus ángulos (polifocalidad). Eso lo aprendió muy bien Nicanor Plaza. Un buen espectador de escultura, para captar el mensaje encerrado en ella, debe poder percibirla desde el máximo posible de puntos de vista, debe recorrerla.

El Caupolicán pasa con honores el examen de la tridimensionalidad, mostrando al espectador distintas facetas de su mensaje escultórico, que cambia de lugar y que en este caso, por estar instalada en un cerro, tiene además la posibilidad de variar los niveles de altura para la observación. Eso significa que se puede mirar desde arriba o desde abajo, según dónde se sitúe el espectador entre las distintas rocas conectadas por las escaleras de piedra.

Si pudiéramos hablar de la escultura como un arte que es percibido en una dimensión de temporalidad, como la música o el teatro, diríamos que el espectador debería comenzar por mirar la espalda y paulatinamente moverse hacia otros puntos de observación para, finalmente, confrontar su propia mirada con la de la estatua, que es el punto final o desenlace de los actos anteriores. En la escultura figurativa o abstracta, como en el teatro, los actos no son menores que el desenlace. Como consecuencia de lo anterior, podemos decir que la escultura crea, trasforma la plaza en un espacio desde donde el espectador, al observar su vista frontal, puede captar en plenitud el mensaje de la obra, su desenlaceacto final que se centra en los ojos del personaje. Luego, tendrá que darse vuelta para entender qué está mirando la estatua, y su mirada, como la del indio, atravesará la plaza, abriéndose en forma triangular en el ángulo de la visión, para cruzar el valle de Santiago y rematar en la cordillera, en el monte San Ramón.

\section{CONCLUSIÓN}

En el fondo del pozo de la historia, como un agua más sonora y brillante, brillan los ojos de los poetas muertos.

Pablo Neruda, «Viaje al corazón de Quevedo»

Este diálogo con Gazitúa, quien cree firmemente que el hilo de la escultura no se corta, celebra los aportes del período postestatuario y afirma que la escultura de hoy no existiría sin el trabajo y la enseñanza de los maestros académicos que trabajaron cien años atrás. Este viaje al «pozo de la historia» en busca de la específica sabiduría, manual e intelectual del lenguaje escultórico, reencuentra a Nicanor Plaza y a Francisco Gazitúa con las concepciones y preceptos que aluden a la identidad y a la esencia del arte del volumen. La mirada a El Caupolicán encierra esa verdad, esa tradición. En la búsqueda de Nicanor Plaza, algo así como el bisabuelo escultórico de Gazitúa, está el inicio del recorrido de la tradición de la estatuaria nacional: del maestro de La Quime- 
ra, toma el testimonio su discípulo Virginio Arias, de ahí Samuel Román, hasta llegar a Gazitúa.

La larga trayectoria artística y docente de Plaza le otorga una jerarquía de maestro fundacional de la enseñanza y el arte estatuario en el país. Fue incansable en enseñar y en hacer, hasta su muerte en Florencia. En 1871 había sido llamado por el gobierno chileno para encargarle la cátedra de Escultura que había dejado François. En sus largos años de docencia pudo formar a varios discípulos, entre los que se cuentan Virginio Arias, Arturo Blanco, Carlos Lagarrigue, Ernesto Concha, Guillermo Córdova y Simón González.

Si éste es un escrito sobre el legado docente, sección aprendizaje de Nicanor Plaza, que quede claro que por lejos que haya ido en su búsqueda, por profundo que haya descendido en el pozo de la historia de la escultura, Gazitúa sale del fondo con las manos vacías, quizás solamente con la conciencia de que lo único que importa en la educación de un artista - escultor-, más allá de todos los programas y las escuelas, es crear condiciones para su «pacto a muerte» con el oficio. Plaza lo hizo, fue el primero en hacerlo en la escultura chilena. Ese pacto fue quizás lo más importante de su aprendizaje y la esencia de su legado docente, lo dejó pegado a los ladrillos de la Facultad que fundó.

\section{REFERENCIAS}

Blanco, Arturo. Cartas del Escultor José Miguel Blanco. Santiago: Imprenta Las Artes Mecánicas, 1907. Medio impreso.

Carvacho, Víctor. Historia de la escultura en Chile. Santiago: Editorial Andrés Bello, 1983. Medio impreso.

Cicarelli, Alejandro. «Discurso pronunciado a la apertura de la Academia de Pintura por su Director D. Alejandro Cicarelli, 7 de marzo de 1849». Anales de la Universidad de Chile VI (1849). 105-117. Medio impreso.

Descarnes, Robert. Aguste Rodin. London: Macmillan Edit, 1967. Medio impreso.

Gazitúa, Francisco y otros. Escultura chilena contemporánea 1850-2004. Santiago: Ediciones Arte Espacio, 2004. Medio impreso.

Grez, Vicente. Las Bellas Artes en Chile. Catálogo para la Exposición Universal de París, Sección Chilena. Traducción de Susana Naranjo Parra y Carol Pérez. Santiago: sin editorial, 1889. Medio impreso.

Gutiérrez Viñuales, Rodrigo. Monumento conmemorativo y espacio público en Iberoamérica. Madrid: Cuadernos Cátedra, 2004. Medio impreso.

Jagger, Sargeant. Modelling and sculpture in the making. London: The Studio Limited, 1935. Medio impreso.

Meltcherts, Enrique. Introducción a la escultura chilena. Valparaíso: Talleres de Ferrand e Hijos Ltda., 1982. Medio impreso.

Reglèment École Nationale Des Beaux-Arts, Ministère de L'Instruction Publique Des Beaux-Arts Et Des Cultes. París: Delalain Frères Èditeurs, 1908. Medio impreso.

Suárez, José Bernardo. Tesoro de Bellas Artes. Santiago: Imprenta Chilena, 1872. Medio impreso. 
IOO

Yáñez Silva, Nathanael. "Mármoles de Nicanor Plaza». Revista Zig-Zag, 25 de noviembre de 1916. Medio impreso.

Vicuña Mackenna, Benjamín. «El arte nacional i su estadística ante la Exposición de 1884 (Revista Retrospectiva) 1858-1884». Enrique Solanich. Documentos de la Historia del Arte en Chile, Santiago: Ediciones AICA, 2009. Medio impreso.

Vicuña Subercaseaux, Benjamín. La ciudad de las ciudades (correspondencia de París). Santiago: Sociedad Imprenta y Litografía Universo, 1905. Medio impreso.

Voionmaa Tanner, Liisa, Escultura pública: del monumento conmemorativo a la escultura urbana. Santiago 1792-2004. Santiago: Ocho Libros Editores, 2004. Medio impreso.

Recepción: 6 de octubre de 2010

Aceptación: 5 de abril de 2011 